\title{
THE TRANSPLANTATION OF OVARIES IN CHICKENS
}

\author{
C. B. DAVENPORT
}

From Carnegie Institution of Washington: Station for Experimental Evolution

Dr. C. C. Guthrie ('08) has reported the results of transplanting ovaries from black to white hens and vice versa. A blackplumaged hen furnished by transplantation with 'white' eggs and mated to a white cock gave "about equal numbers of white and spotted" chicks. Guthrie thinks that these black spots indicate that the black-plumaged foster-mother infected the engrafted 'white' eggs. So far Guthrie. But a person familiar with the results of hybridizing will appreciate that Guthrie's result is better explained on the assumption that the engrafted ovary was absorbed and that the white sperm fertilized the regenerated 'black' eggs of the black hen. For the white by black cross gives white offspring. with black spots in the female chicks only, i.e., half of all, as Guthrie found.

In a second set of experiments, Guthrie found that when a white hen carrying a 'black' ovary was mated to a White Leghorn male, the offspring were either white or black or spotted. Guthrie says: "The black, therefore, must have come through the black ovary." But the student of hybridization on poultry will recognize at once that, if the white-plumaged cock produced only 'white' germ cells, none of his offspring would be black even if the eggs were 'black.' Hence, the cock must have had 'black' germ cells and, very likely, the hen also, since 'White Leghorn' hens that carry 'black' germ cells are very common and frequently show, in adult life, a pure white plumage.

If two 'White Leghorns' with 'black' germ cells be mated expectation is that in four chicks one shall be black; one spotted, and

${ }^{1}$ A preliminary paper covering these results was read before the Society ior Experimental Biology and Medicine, June 1910. 
two white; Guthrie got five chicks, one black, one spotted and three white.

Guthrie found that a black hen containing a 'white' ovary, mated with a black cock gave black-plumaged chicks, of which two out of six had white feet. He concludes that the white condition of the feet must have come from the engrafted eggs of the White Leghorn. In criticism it must be pointed out that the cross, white egg $\times$ black sperm, normally gives offspring whose plumage color is white, either pure or with black specks. The fact that all the offspring had black plumage proves that the eggs were the normal 'black' eggs regenerated by the black hen. The white toes are frequently found in the offspring of two black birds. Thus in my pen 1041 two extracted blacks (Sumatras) mated give ten black chicks in six of which white toes are recorded. The results of this cross of Guthrie's confirm the conclusion that the transplanted ovaries were not functional and that the normal ovaries had regenerated.

To test the possibility of such regeneration of ovaries I removed the ovaries of some hens in the autumn of 1909 and transplanted into them eggs from dissimilar hens. The operated birds were then mated to cocks resembling the soma of the so-called 'fostermother.' Were there regeneration of the ovary the offspring should be of the straight breed; but if the 'grafts' persisted and became functional the chicks should be hybrids.

Experiments 1 and 2, operations: The protocol of the grafting operations is as follows:

No. 11379, pure-bred Dark Brahma bantam, hatched February, 1909; made to fast two days. On September 29, 1909, injected with 0.005 grain of atropin in 1 cc. of water, etherized in about twelve minutes and opened up between two left intercostals. Large ovary, badly torn in removal, removal tolerably complete. One piece of ovary from no. 11605 fastened by cotton thread to mesentery near attachment of ovary. Sewed up.

No. 11605, hatched March, 1909, from White Leghorn,-Houdan ancestry. Clean-footed, with five toes on each foot, $V_{\text {-comb, }}$ modified high nostril, plumage color white (with black recessive). On September 29, 1909, injected 0.005 grain atropin in 1 cc. of 
water. Etherized in twenty minutes. Plucked feathers and opened body wall between last two ribs. Large ovary completely removed or nearly so, in three or four pieces. Hemorrhage slight. Stitched in small piece of ovary of no. 11379 to peritoneum near attachment of old ovary. Sewed up. Bird recovered rapidly. Some Dark Brahma in ancestry, but its characters had become eliminated.

Results, Experiment 1. Mated in pen 1027, no. 11605 ᄋ (with engrafted ovary from no. 11379, Dark Brahma) and 11291 ${ }^{\circ}$, straight Dark Brahma. Table 1 gives the juvenile characteristics of 1 , the male; 2 , the White Leghorn-Houdan, so-called foster-mother; 3 , the hen from which the ovaries were transplanted; 4, expectation on the hypothesis that the graft succeeded; 5, expectation on the hypothesis that the graft failed and the proper ovary was regenerated; and 6 , the observed characteristics of the young offspring.

An examination of table 1 shows at once that it cannot be true that the engrafted ovary replaced the hen's proper ovary, for if it had, columns six and four should agree. On the contrary, column six agrees essentially with column five and supports the hypothesis that the engrafted eggs did not become functional.

One discordant fact there is, however, namely, the occurrence in column six of three cases of cinnamon offspring. Such offspring are to be expected on the hypothesis that some eggs of the graft became functional. If that hypothesis be true, then the other characters of the same individuals should be like those of the pure Dark Brahma. Of the three the first has extra toes, split comb and a boot of one row; it is no Dark Brahma; the second has extra toes, wide nostril and a two rowed boot; it is not a Dark Brahma; and the third has really black down with some red at the tips, five toes on the right foot, a split comb and one row of feathers on the shank; so it is not a Dark Brahma. These therefore, are not from the engrafted Dark Brahma eggs. They represent cases of imperfect dominance of the black down over cinnamon. The conclusion to be drawn from this experiment is that the engrafted eggs did not mature in the foster-mother. 


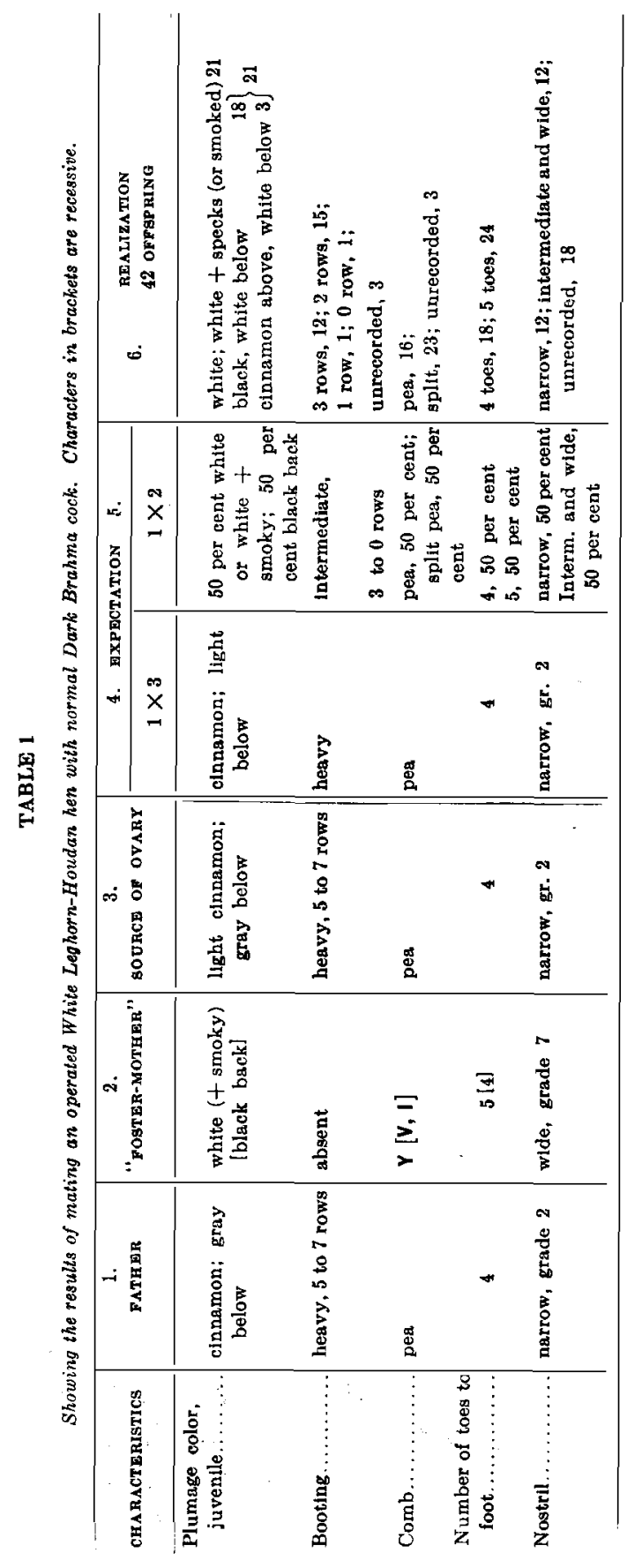


Experiment No. 2. No. 11379, Dark Brahma with engrafted ovary from no. 11605 (White Leghorn-Houdan) was mated in pen 1050 with $14122^{\circ}$, a single-comb Black Minorca. Table 2 gives the juvenile characters of 1 , the male parent; 2 , the Dark Brahma, so-called foster-mother; 3 , the hen from which the ovaries were transplanted; 4 , the expectation of offspring on the assumption that the graft succeeded; and 5 , that the graft failed and the proper ovary was regenerated; also, 6 , the observed characters in the offspring.

Without exception the characters of the offspring are clearly those of the Dark Brahma $\times$ Minorca cross and none of the White Leghorn or Houdan differential characters enter into their composition. The grafted ovary produced no eggs that developed, the extirpated ovary was regenerated.

Experiments 3 and 4, operations. The protocol of the grafting operations is as follows:

No. $11541 \%$ is a white-plumaged hen derived from a cross between $8681 \&$, a WhiteLeghorn-Minorca-Polish bird, and $7811 \sigma^{7}$, a Houdan cross hatched (in pen 905) in February, 1909; fasted two days. On October 2, 1909, injected with 0.005 grain atropin in 1 cc. of water; etherized and opened. Ovary very large, two large pieces (60 per cent) of ovary removed. Strong hemorrhage. Two small pieces of ovary from no. 11383 \%, Dark Brahma, sewed with peritoneum close to ovarial artery. Sewed up. Bird slow in recovery.

No. $11383 \%$, straight Dark Brahma, hatched February, 1909, from mating 907: 7549. On October 2, 1909, injected with atropin, etherized and opened, ovaries small, incompletely removed. Two large pieces of ovary of no. 11541 sewed into peritoneum. Sewed up. Bird recovered rapidly.

Results, experiment 3. No. 11541, White Leghorn-Black Minorca-Polish-Houdan hybrid, with engrafted ovary from No. 11383, Dark Brahma, was mated in pen 1027 with $11291 o^{7}$, a pure bred Dark Brahma. The results of this mating are given in table 3.

Experiment 4. No. 11383 , pure-bred Dark Brahma with engrafted ovary from no. 11541 (White Leghorn-Black Minorca- 


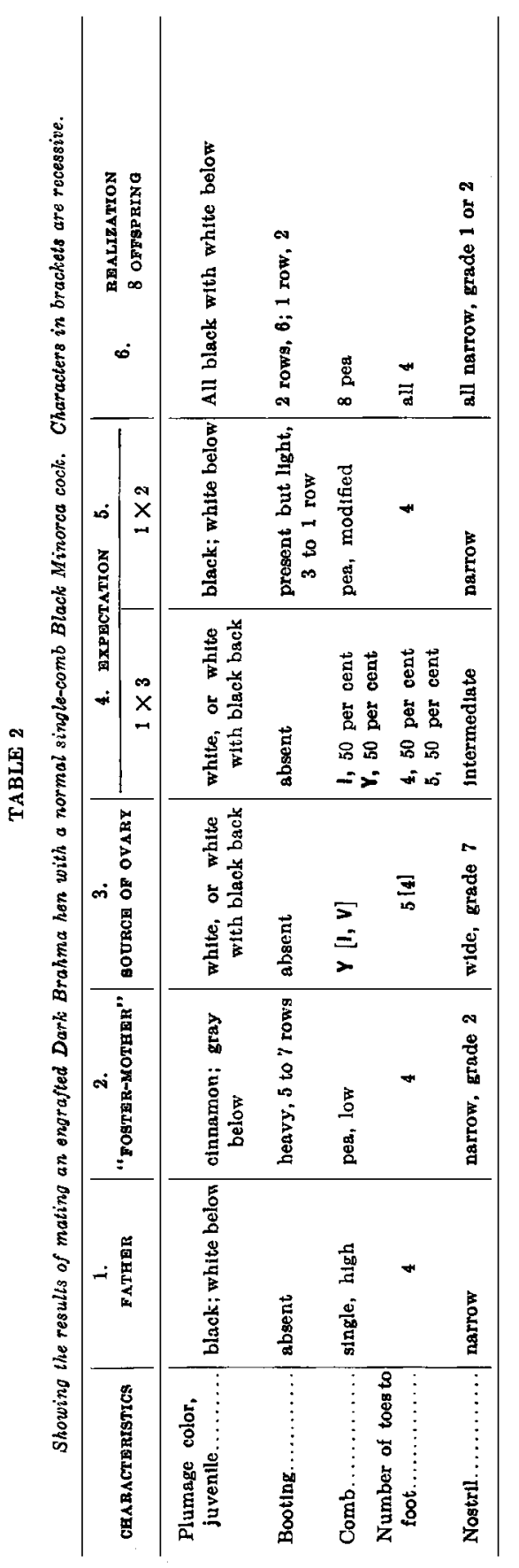




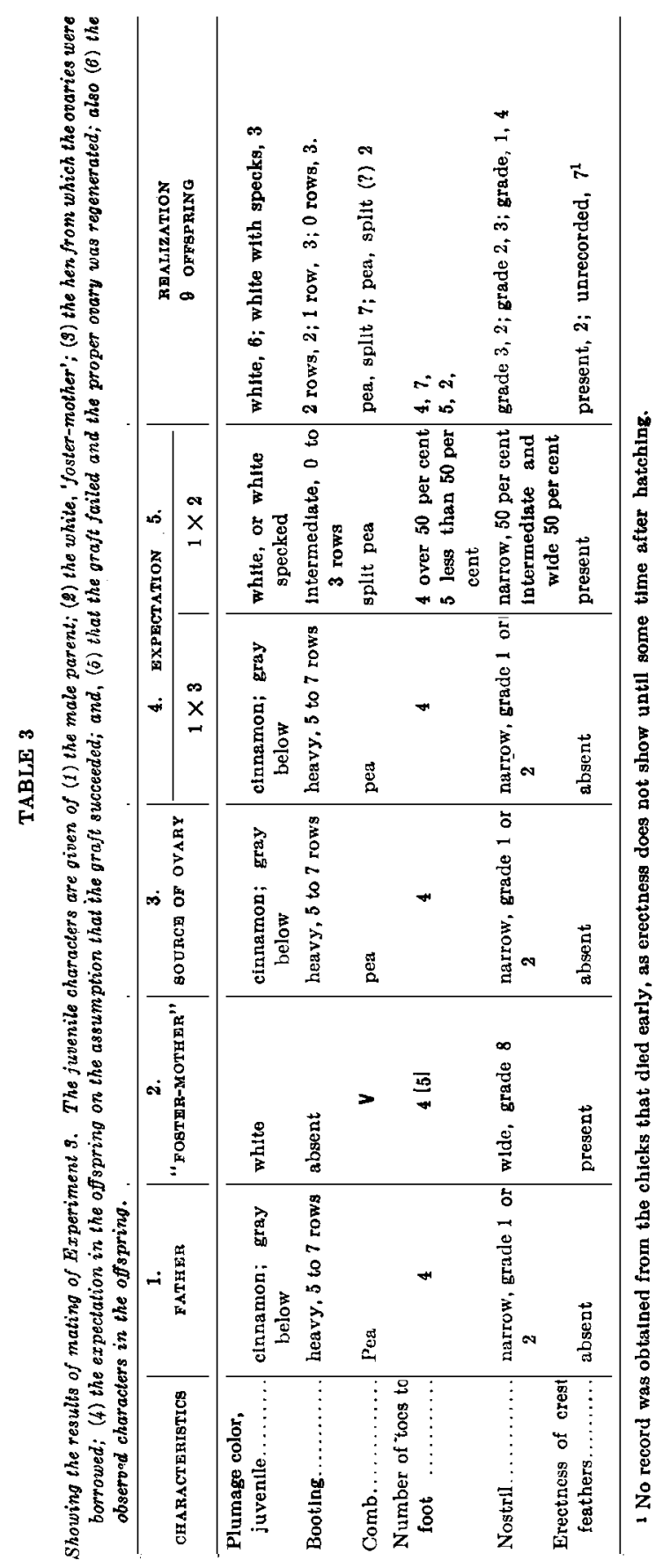


Polish-Houdan hybrid) was mated with a Black Minorca $14122 \sigma^{5}$. The results of this mating are given in table 4 .

Experiment 5. No. 11693 \%, used in this experiment, is a white bird that had 'smoke' on down when hatched. It is of somewhat complex origin. Its mother was an $\mathrm{F}_{1}$ hybrid between a Black Spanish cock and a White Leghorn; its father had the same elements and also white Silkie in its ancestry. No. 11693 has, consequently, black recessive. It has a single comb, is free of the skin pigment of the Silkie, is clean-shanked and has four toes on the right foot and five on the left.

On September 19, 1909, this pullet (which was hatched March, 1910) was treated with atropin, etherized during half an hour and opened as usual between the last two ribs. All of the ovary, as far as could be seen, was removed. Pieces of ovary from no. 11280 \& (a straight-bred Dark Brahma bantam) were placed in contact with the peritoneum, near the removed ovary, but not stitched in, as the bird showed signs of succumbing. The cut was sewed up and the bird set aside where it lay quiet for half an hour. ${ }^{2}$ The Dark Brahma from which the ovary (whose eggs measured $0.5 \mathrm{~mm}$. in diameter) was removed died in consequences of hemorrhage.

Later No. 11693 was mated with 11291 or (in mating 1027: 11693). He is a straight-bred dark Brahma bantam cock, used also in experiments 1 and 3 . The results are shown in table 5.

Experiment 6. No. 11826 \%, hatched March, 1909, a pure bred Dark Brahma was opened October 2, 1909, and ovary imperfectly removed. Ovary of no. 12550 (aWhite Leghorn-Minorca-PolishHoudan hybrid) sewed on to peritoneum at point of removal. The ovary had been kept out of body of hen about ten minutes, but covered and moist.

In the late winter of 1910 no. 11826 o was mated in pen 1050 with 14122 o, a single-comb Black Minorca. The results are given in table 6 .

${ }^{2}$ See postscript. 


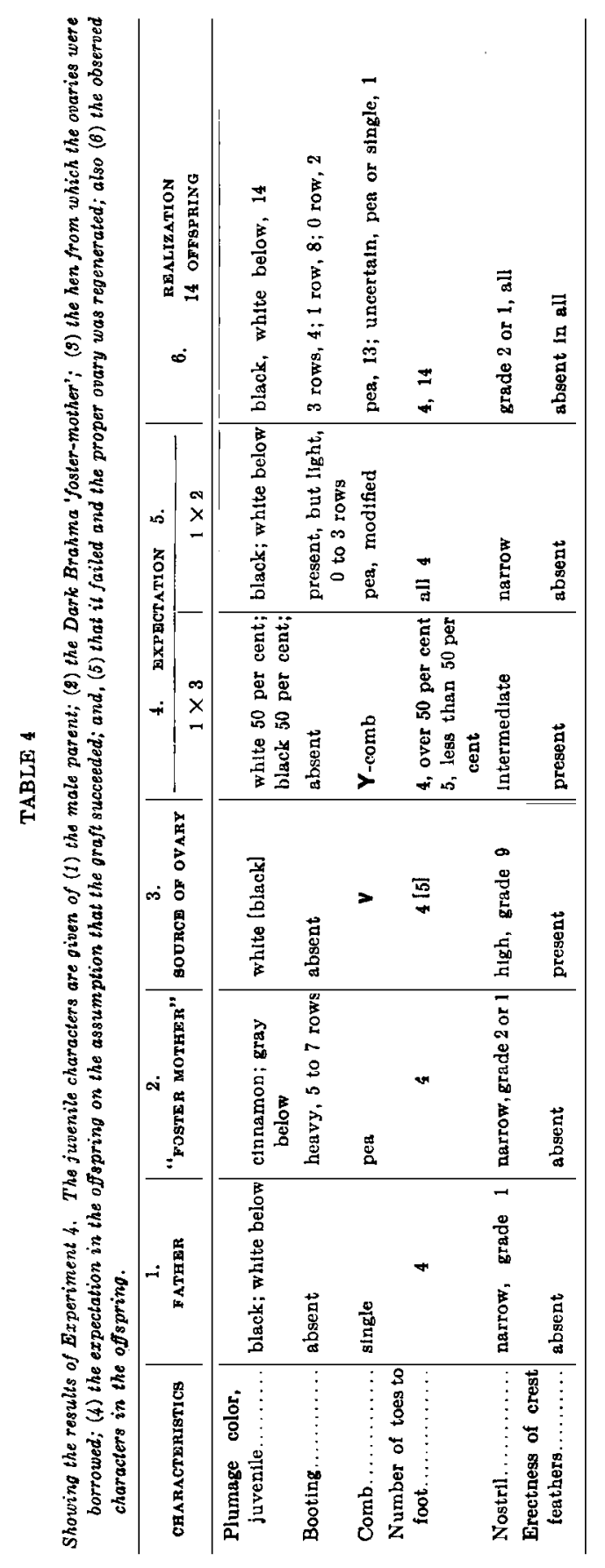




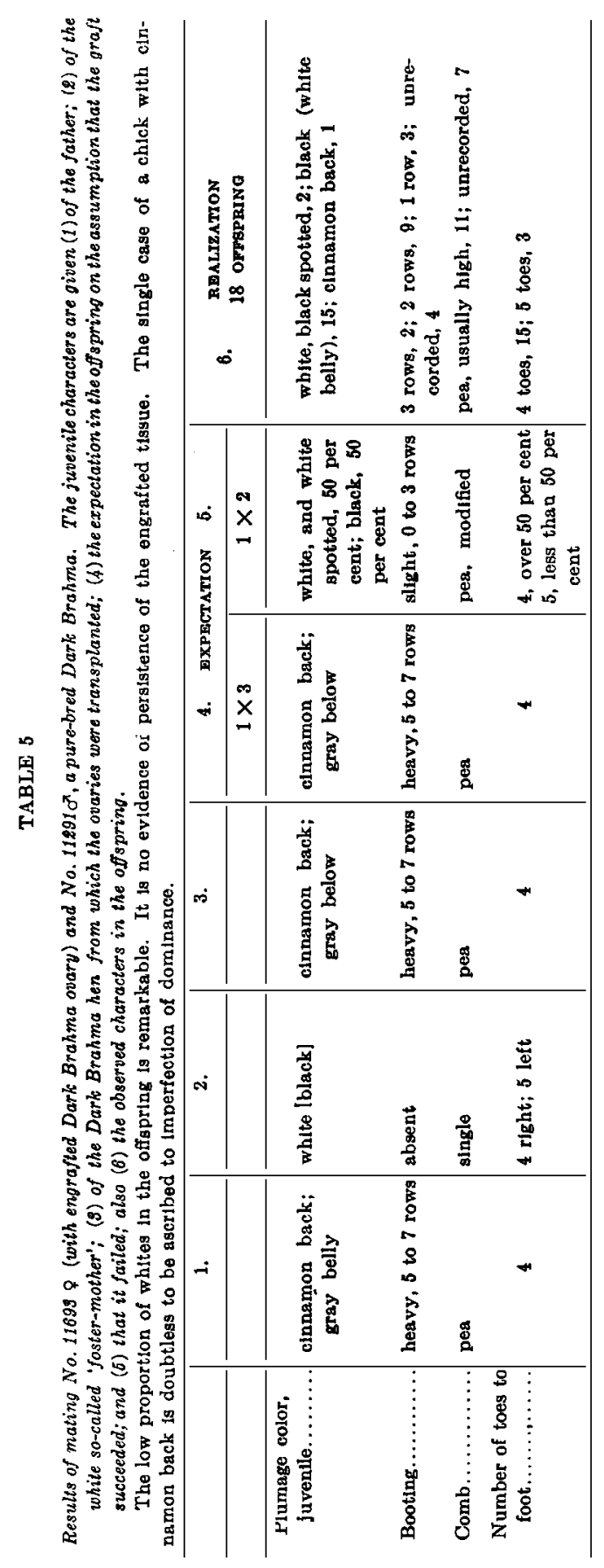




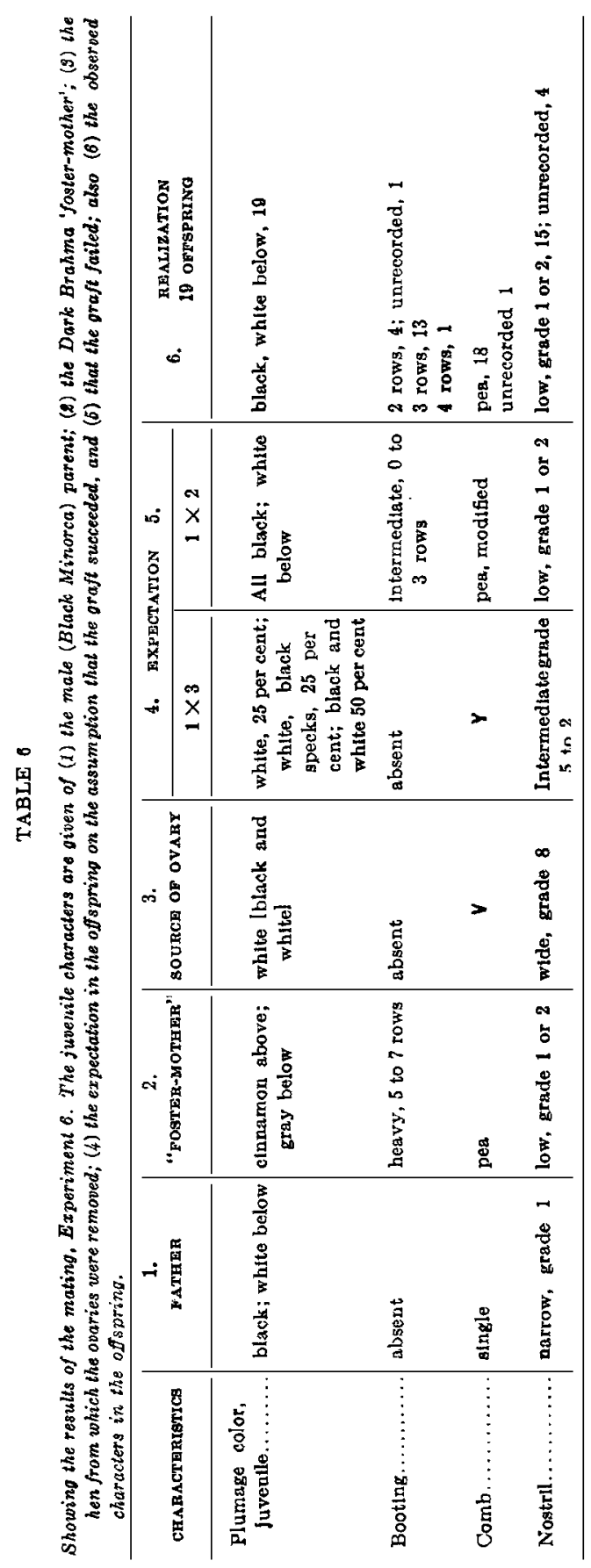

JOURNAL OF MORPHOLOGT, VOL. 22, NO. 1 


\section{CONCLUSIONS}

In the six experiments described above there is no evidence that the engrafted ovary ever became functional but all results are in accord with the conclusion that the more or less completely extirpated ovary regenerated and produced an abundance of eggs. With the results the data of Dr. Guthrie's paper are not in disaccord. His data, like ours, furnish no evidence for the survival of the engrafted ovaries, far less of an effect of the soma of the foster-mother on the introduced germ plasm.

Cold Spring Harbor, N. Y.

September 26, 1910.

\section{POSTSCRIPT}

On January 4, 1911, No. 11693 was killed and opened on the left side. An ovary of fairly typical size for a hen entering her second year of laying was found. It contained numerous eggs, 4 to $5 \mathrm{~mm}$. in diameter. Slightly ventrad of the main artery of the ovary is an irregular mass $5 \times 4 \times 2 \mathrm{~mm}$. of cheesy consistency, imbedded in and covered by peritoneum. Its general appearance is that of a dried, hardened ovary, with clear traces of follicles. It doubtless represents the engrafted ovary, entirely encysted in the peritoneum.

January 30, 1911.

\section{LITERATURE CITED}

Davenpont, C. B. 1906 Inheritance in poultry. Publication no. 52, Carnegie Institution of Washington.

1910 Inheritance of plumage color in poultry. Proc. Soc. Exper. Biol. and Med., vol. 7, p. 168.

Guthrie C. C. 1908 Further results of transplantation of ovaries in chickens. Jour. Exp. Zoöl., 5, pp. 563-576. 